Article

\title{
Bicycle-Bicycle Accidents Emerge from Encounters: An Agent-Based Approach
}

\author{
Gudrun Wallentin * and Martin Loidl \\ Department of Geoinformatics - Z_GIS, University of Salzburg, Hellbrunnerstraße 34, 5020 Salzburg, Austria; \\ martin.loidl@sbg.ac.at \\ * Correspondence: gudrun.wallentin@sbg.ac.at; Tel.: +43-662-8044-7514
}

Academic Editor: Jake Olivier

Received: 25 February 2016; Accepted: 13 June 2016; Published: 21 June 2016

\begin{abstract}
Traditional accident risk prediction models need adequate data on explanatory variables, most importantly data on traffic flows. However, in the case of accidents between bicycles the availability of such data is often limited. Therefore, alternative bottom-up simulation modelling approaches are expected to complement traditional equation-based models. In this paper we present an agent-based approach to explore bicycle-bicycle accidents. Specifically, we hypothesise that (1) bicycle-bicycle accidents are based on the population of encounters between cyclists rather than on bicycle flows and (2) that encounters have a non-linear relationship with flows. Bicycle flows and encounters are simulated by means of an agent-based model that is implemented for the road network of the city of Salzburg. Simulation results are tested against a 10-year dataset of police records on bicycle-bicycle accidents. The results affirm both hypotheses: First, cyclist encounters exhibit a linear relationship to accidents and thus suggest being the true population of bicycle-bicycle accidents. Second, flows show a relationship in the form of a second-order polynomial function with encounters as well as accidents.
\end{abstract}

Keywords: bicycle safety; bicycle accidents; agent-based model

\section{Introduction}

Collisions between bicycles have not received much attention in the literature as compared to accidents that also involve motorised vehicles. However, due to under-reporting of bicycle accidents, they are likely to be underestimated in official statistics [1]. Furthermore, as cycling becomes more popular and more bicycle path infrastructure is offered, safety on bicycle paths is expected to become increasingly important [2].

From a methodological perspective, bicycle accident risk models-just as any other accident risk model-aim to explain the occurrence of accidents, usually with the help of explanatory variables. The variable with the most explanatory power therefore is traffic volume [3]. The more traffic there is, the more accidents can be expected. However, this is a non-linear relationship [3-5]. For example, Martin [6] showed that for car accidents in which two or more vehicles are involved, the rate of accidents per road user increases with the number of road users. Jacobsen [7], in contrast, describes the safety in numbers phenomenon, where the individual accident risk of a cyclist with a motorized vehicle declines with the number of bicyclists around. It is under debate whether this non-linear correlation is due to the adaptive behaviour of motorists or to differences in the infrastructure design of the compared locations [8]. Greibe [3] reports that the flow in accident risk models needs to be raised to a power, with power values typically ranging between 0.8 and 1.0 for urban roads. In accordance with the 'safety in numbers' phenomenon this results in a decreasing accident rate for increasing traffic volumes. Eenink, Reurings, Elvik, Cardoso, Wichert and Stefan [4] report an even smaller power value of 0.32 for urban roads in the Netherlands. Usually, the models are calibrated with data by means 
of probabilistic methods such as logistic regression, Bayesian modelling, Markov chains or neural networks [9-11]. Given that enough adequate calibration data for explanatory variables are available, accident prediction models can be highly accurate and can explain up to $60 \%$ of accidents [3].

Analysis of the risk of bicycle-bicycle accidents is likely to be limited by data scarcity. In most cities, bicycle traffic flow data are incomplete or virtually non-existent [12]. Other data sources such as voluntarily collected bicycle accident data exist, but are mostly restricted to sportive leisure cycling [13]. Also, bicycle accidents statistics are characterised by severe under-reporting. Only a fraction of bicycle accidents that result in hospitalisation are reported to the police [1,14]. Minor accidents are even less likely to be included in official statistics $[15,16]$. Online platforms to collect voluntary reports on bicycle accidents or near misses have been developed recently [17], but to date contain only few reports. In the case of such data scarcity, explanatory models on bicycle accidents are hard to calibrate and their predictive power is poor, especially for bicycle-bicycle accidents.

Scarcity of bicycle data is also true for the city of Salzburg, which serves as the test bed for the present study. The city administration provides data from six bicycle count stations, but there is no empirical data on the city-wide distribution of bicycle flows [18]. Therefore, the prediction of bicycle accidents is expected to benefit from alternative modelling approaches that are less data-driven, although a caveat remains regarding potential biases in the police accident reports, which serve as validation data [19].

Generally, agent-based modelling has gained popularity as an alternative approach in transport modelling [20-24]. A major difference between agent-based models (ABM) and equation-based models is their bottom-up approach: bottom-up transport models are based on individual road participants that move and interact in a highly disaggregated representation of the road network. ABMs are rooted in complexity theory, which suggests that system-level patterns emerge from the rule-based interaction of individual entities [25]. Traffic flows are not modelled by mathematical equations, but they emerge from the stepwise simulation of dynamic behaviour of individual road participants interacting on a spatially heterogeneous road network [26]. Due to the fine spatial and temporal resolution of the simulation, ABMs cannot only simulate flows, but also individual encounters of two vehicles on a road network. For traffic safety research this is important, as an accident can only occur if the trajectories of two road participants cross. Each crossing trajectory is tagged as an encounter (passing, overtaking, or crossing). The relation between encounters and accidents has been used to study road safety based on interactions at the local scale [27], e.g., at specific intersections [28], roundabouts [29], or in abstract traffic environments [30]. However, to the best of our knowledge, simulated encounters have not been explored for their adequacy as exposure variables compared to conventionally used traffic flows for large networks on the scale of an entire city.

In this paper, we use an agent-based modelling approach to simulate two alternative spatio-temporal datasets to represent the populations at risk for bicycle-bicycle accidents: (1) bicycle traffic flows and (2) bicycle-bicycle encounters. We then compare the two simulated populations with accidents reported by the police. We hypothesise first that the number of bicycle-bicycle encounters is the true statistical population for accidents between bicyclists, which thus have a linear relationship with observed accidents; and second that flow volumes have a non-linear relationship with encounters and thus also have a non-linear relationship with observed accidents. The general idea is exemplified with an agent-based model that is first implemented in an abstract network graph and then applied to the city of Salzburg, Austria. A dataset of all bicycle accidents in the city of Salzburg that were reported to the police between the years 2002 and 2011 was available to test the hypotheses. 


\section{Methods}

\subsection{Overall Approach}

Bicycle traffic flows and respective encounter points were simulated by means of the Agent-based Bicycle Traffic Model that has been successfully applied to the city of Salzburg [18]. For this research, the existing model was extended to not only compute cyclist counts per time (flows), but also to record points at which cyclists meet (encounters).

The overall workflow is visualised in Figure 1. First, the Agent-based Bicycle Traffic Model was implemented on a simple, abstract network to explore the general relation between flows and encounters. The network is represented by a graph, which consists of nodes (junctions in a real-world context) and edges (representing road segments). Second, the model was used to simulate encounters of cyclists on the road network graph of the city of Salzburg. Both models were implemented in the NetLogo modelling framework [31]. The simulated results for the city of Salzburg were then plotted against police reported accident data. Assuming that the population at risk explains a large part of accidents, we expected to gain insights on the true nature of the population at risk from contrasting flows versus encounters in relation to accidents. Accident data in the present study exclusively referred to police-reported bicycle-bicycle accidents between the years 2002 and 2011. This dataset comprised $14 \%$ of all police-reported bicycle accidents. In the 10-year study period we assumed stable conditions and we did not account for any variations in, e.g., weather, infrastructure or cycling preferences.

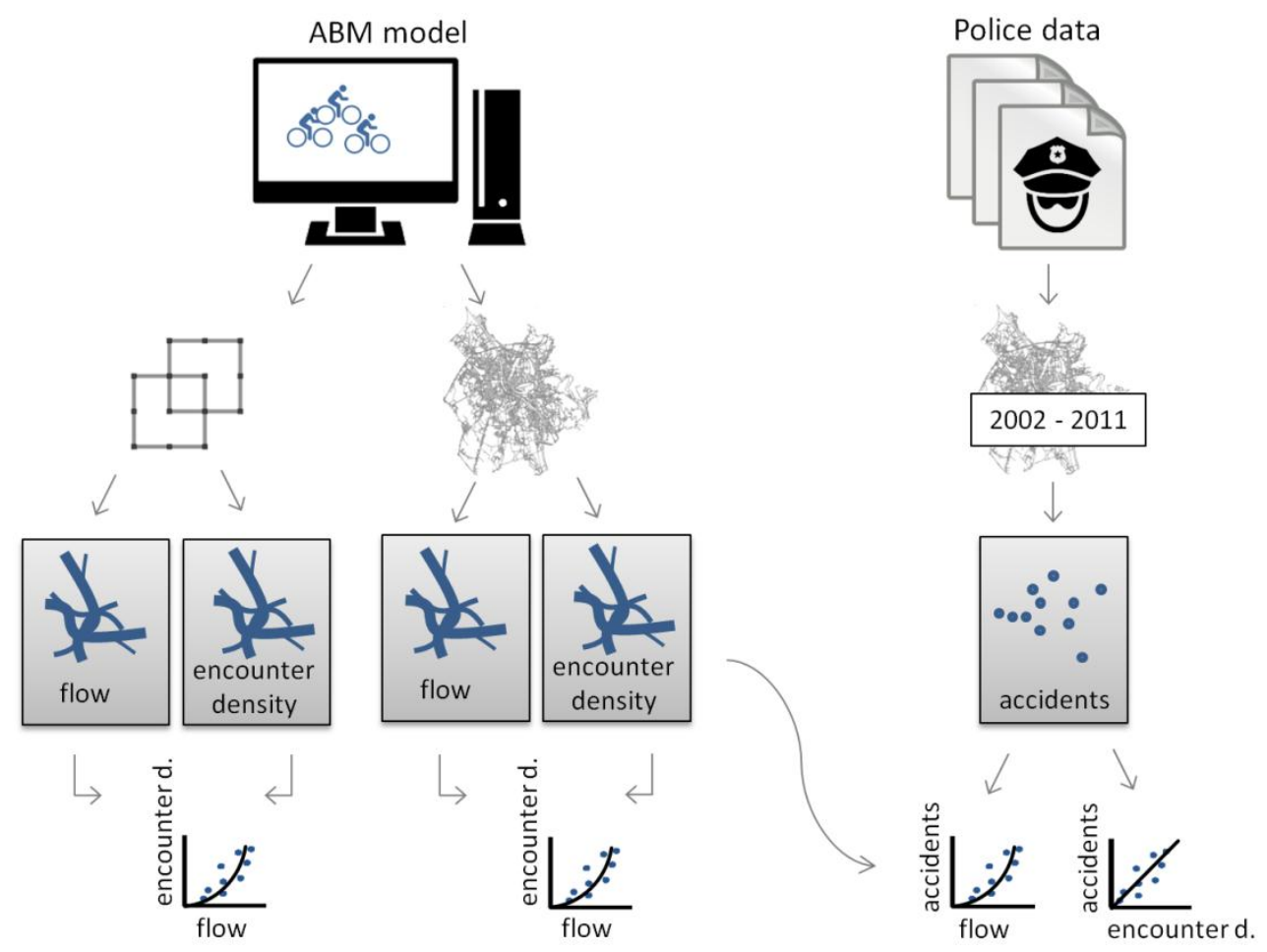

Figure 1. The diagram shows the overall approach of this paper. The relation between simulated flows and simulated encounters is explored. Then, the hypothesis is tested that encounter density more adequately represents the statistical population from which accidents emerge compared to commonly used flows. The relationship between flows and accidents is expected to be quadratic, whereas the relationship between encounter densities and accidents is expected to be linear.

\subsection{Flows and Encounters in an Abstract Network}

Conceptually, if all road users meet each other once, the relation of encounters can be described as the sum of natural numbers: Two cyclists can have only one encounter (C1 with $\mathrm{C} 2)$. Three cyclists 
have three encounters ( $\mathrm{C} 1$ with $\mathrm{C} 2$ and $\mathrm{C} 3+\mathrm{C} 2$ with $\mathrm{C} 3$ ). Four cyclists have six encounters, etc.; $\mathrm{n}$ cyclists therefore encounter $\mathrm{n} \times(\mathrm{n}-1) / 2$ times. This relation between cyclists and encounters can be described mathematically in the form of a second-order polynomial function:

$$
-0.5 \times \mathrm{n}+0.5 \times \mathrm{n}^{2}
$$

where $\mathrm{n}$ is the number of cyclists.

In a network of many nodes, one cyclist meets only a fraction of other cyclists, depending on the number of nodes and the connectivity in the network. We would therefore expect the relation between flows and encounters to be of the general form of $a \times n+b \times n^{2}$, where the coefficients $a$ and $b$ are related to the complexity of the network.

To illustrate the relation between flows and encounters with a simple simulation model, the bicycle model was implemented on an abstract network graph (Figure 2). This graph consisted of two intersecting square streets, each of which consisted of eight regular segments of equal length. Street $B$ is well suited for cycling, whereas street A is less suited. In the simulation, a user-defined number of cyclists travelled along these streets over 10,000 time steps. Each time step, a cyclist travelled from one node to another through one street segment. Cyclists could change direction at crossings, but could not make a U-turn to return to where they came from. At a crossing, a cyclist decided in $80 \%$ of the cases to travel street B instead of street A. All cyclists travelled at the same speed, therefore encounters occurred, if cyclists passed, crossed or travelled together.

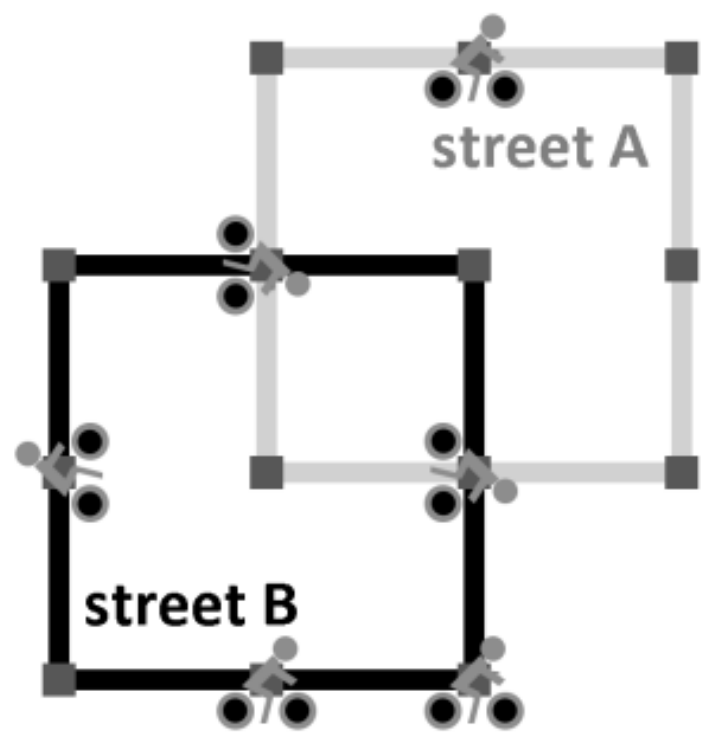

Figure 2. Layout of an abstract street graph to explore general relations between flows and encounters: the grey street A is preferred by only $20 \%$ of cyclist agents, while $80 \%$ decide to travel the black street $\mathrm{B}$.

After 10,000 time steps, the following state variables were recorded for further analysis: number of encounters, proportion of encounters on street $A$ to street $B$, and proportion of travelled segments along street $\mathrm{A}$ to street $\mathrm{B}$. This simulation was repeated for 10 different numbers of cyclists, ranging between $n=1$ and $n=20$.

\subsection{Agent-Based Bicycle Encounter Model for the City of Salzburg}

The extended Agent-based Bicycle Traffic Model was then applied to the city of Salzburg. Each agent cycled from home to its destination (e.g., work or study place) and back again. The resolution of time steps was reduced to one second in order to record all encounters. The spatial resolution of the road graph was continuous. Simulations were computed with multiple numbers of cyclist agents 
per day ranging between 50 and 10,000. The number of simulated trips thus ranged between 100 and 20,000 trips per simulation. Each simulation was run twice, so that in total 24 simulation runs were computed.

After each simulation, the following data were recorded for further analysis: (1) a geospatial point dataset of the encounter locations with the attributes 'time', and 'encounter angle'; (2) a geospatial dataset of the road network graph with the attribute 'number of times traversed' for each segment; and (3) the spatially aggregated number of actively cycling agents and encounter events with a resolution of $15 \mathrm{~min}$. In a post-processing step, encounter angles were coded as one of the following types: overtaking $\left(0^{\circ}\right.$ to $\left.45^{\circ}\right)$, crossing $\left(45^{\circ}\right.$ to $\left.135^{\circ}\right)$, and oncoming $\left(135^{\circ}\right.$ to $\left.180^{\circ}\right)$. The probability that two cyclists from opposite directions crash on an ordinary road is negligible. Therefore, encounter points between oncoming cyclists were excluded, except for bicycle-only infrastructures. As we exclusively focused on the population at risk we did not consider any further risk factors such as road design, trip purpose, or weather condition.

The simulation outcomes were further analysed to identify a potential relation between the number of cyclists and the number of encounters. Therefore, the number of cycling agents per time (flow) was plotted against the simulated number of agents that met (encounters). These flow-encounter pairs were calculated at three spatial and temporal granularities:

- First, the number of cyclists and the number of encounters were aggregated over the entire day for each of the 24 simulation runs. For each simulation, the total number of cyclist agents was plotted against the total number of generated encounter points.

- Second, the simulated results were discretised temporally into 15 min time bins. For each time bin the number of actively cycling agents was plotted against the respective number of encounters.

- Third, simulation results were discretised spatially into individual street segments. For each street segment the number of cyclists that traversed the segment was plotted against the respective number of encounters per metre street length. For this purpose encounters had to be further processed from points to line-based densities. The density was computed as a network-based kernel density using the SANET toolbox [32] with a $10 \mathrm{~m}$ search radius and $10 \mathrm{~m}$ output segment length. To identify potential relations between the number of cyclists and the amount of encounters, trend lines were fitted through the flow-encounters plots.

\subsection{Comparison with Police Record Data}

Finally, simulated flows and encounters were compared with observed bicycle counts and police reported accidents. To explore the temporal match, diurnal traffic dynamics of the simulation were juxtaposed to observed dynamics. To explore the spatial match, maps of simulated flows and simulated encounters were visualised in comparison to a map of the reported accident locations. Finally, simulated flows and encounters were plotted against the reported accidents in one-hour time bins. Trend lines with $68 \%$ confidence intervals were fitted through the data and the number of data points within the confidence intervals was counted to get an indication how well the regression model fits. Further, the residuals were evaluated and the adjusted $R^{2}$ was computed.

\section{Results}

In the abstract street graph model, the number of simulated encounters took the form of a second-order polynomial function with respect to the number of modelled cyclists (Figure 3a). The form of the function resembles our conceptual considerations on encounters in a network (Equation (1)). The goodness of fit expressed by the adjusted $R^{2}$ is equal to one, indicating a perfect fit. However, the parameters are different from Equation (1) as expected, because agents do not encounter each of the other agents in the network at every time step. 
(a)

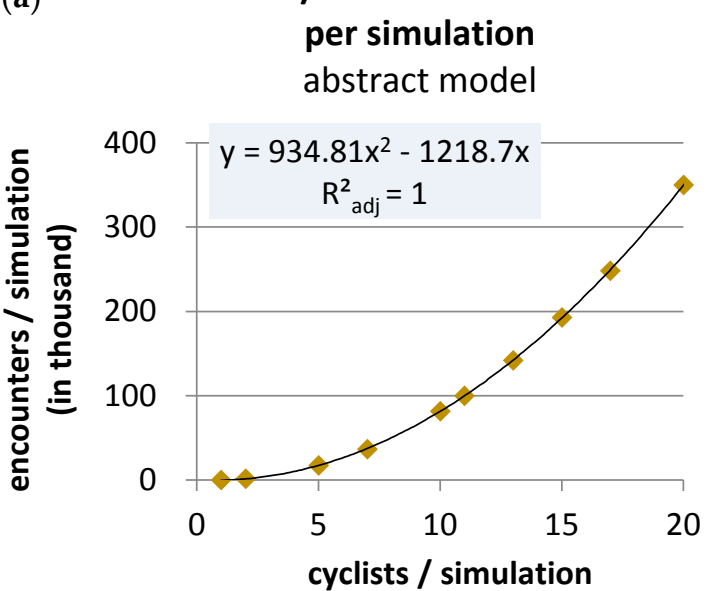

(c)
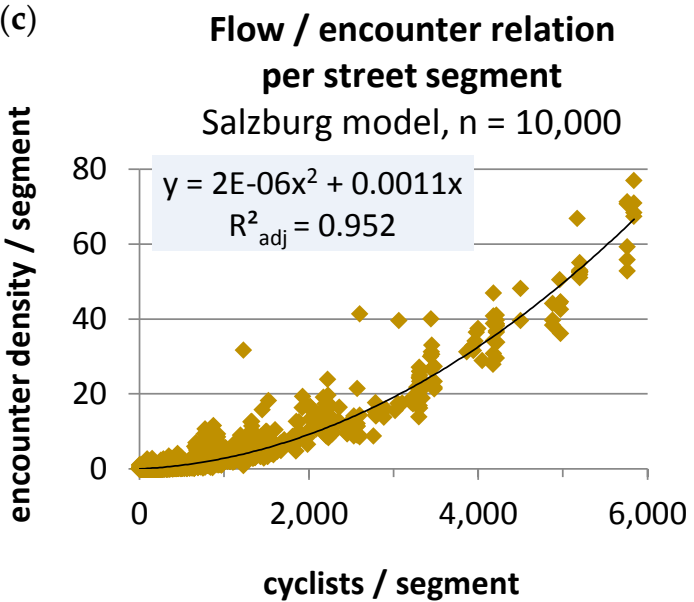

(b)

\section{Flow / encounter relation} per simulation

Salzburg model

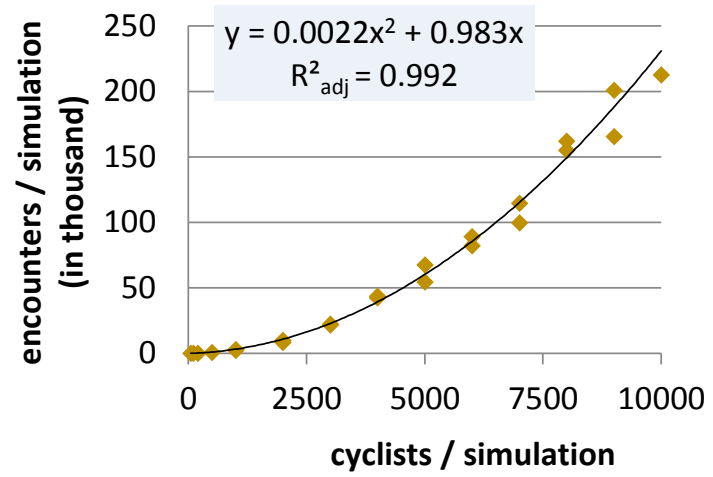

(d)

\section{Flow /encounter relation per time bin}

Salzburg model, $n=10,000$

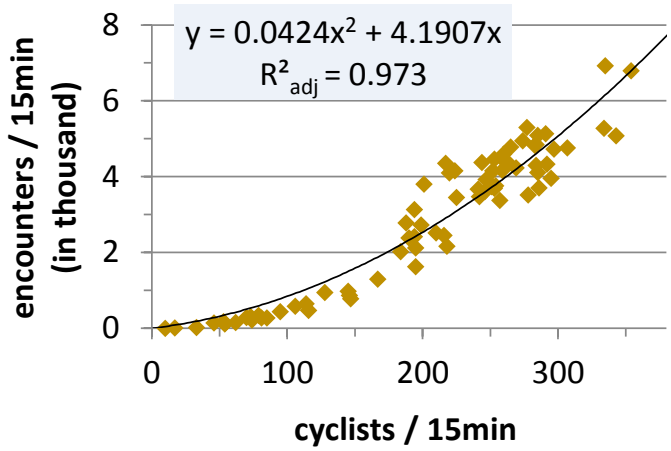

Figure 3. The relation of simulated encounters with the number of modelled cycling agents exhibits a non-linear relationship in form of a second-order polynomial function: (a) encounters vs. cyclists in the abstract street graph; (b) encounters vs. cyclists in 24 simulations of the Salzburg bicycle model; (c) encounter densities vs. cyclists per street segment in the Salzburg cyclist model; and (d) encounters vs. cyclists per quarter-hour in the Salzburg cyclist model.

Next, the Salzburg cyclist model was used to simulate flows and encounters over one day for various numbers of cyclist agents. The model outcomes were analysed analogously to the abstract street graph, i.e., the number of encounters was plotted against the number of simulated cyclist agents. Three further plots resulted from this analysis: The first plot (Figure 3b) shows the relation between the total number of simulated encounters and the respective number of simulated cyclist agents, for the 24 simulation runs. The second plot (Figure 3c) disaggregates the results spatially. The outcomes of a simulation run with the maximum of simulated cyclists $(n=10,000)$ was taken to plot the number of encounters on one metre of street length against the number of simulated cyclists that passed the respective street segment. The third plot (Figure $3 \mathrm{~d}$ ) shows the results in a temporally disaggregated view. It plots the encounter-cyclist pairs for $24 \mathrm{~h}$ at $15 \mathrm{~min}$ time intervals. Through all plots a trend line of the type of a second-order polynomial function was fitted. The trend line exhibited high goodness of fit (adjusted $R^{2}=0.992,0.952,0.973$, respectively).

The non-linear relationship between the number of cyclists and encounters also became apparent when the number of cyclists in the model was juxtaposed with the number of encounters over the course of one day (Figure 4, left). During late-night hours, when there are only a few cyclists on 
their way, the number of encounters was low, whereas encounters increased disproportionally during rush hours. Analysis of the police records unveiled a similar pattern for the observed accidents (Figure 4, right).

\section{Simulated diurnal traffic patterns}

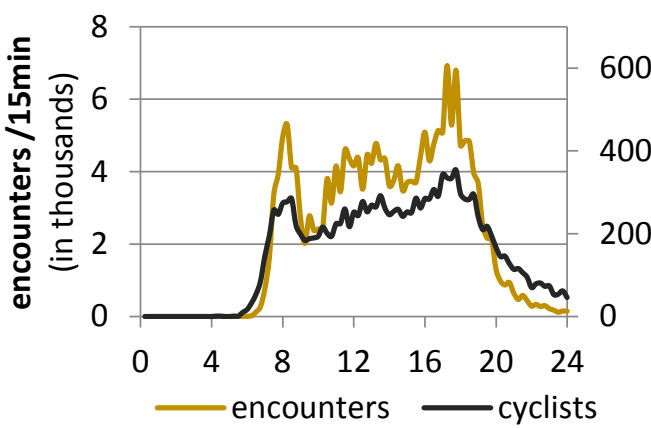

\section{Observed diurnal traffic patterns}

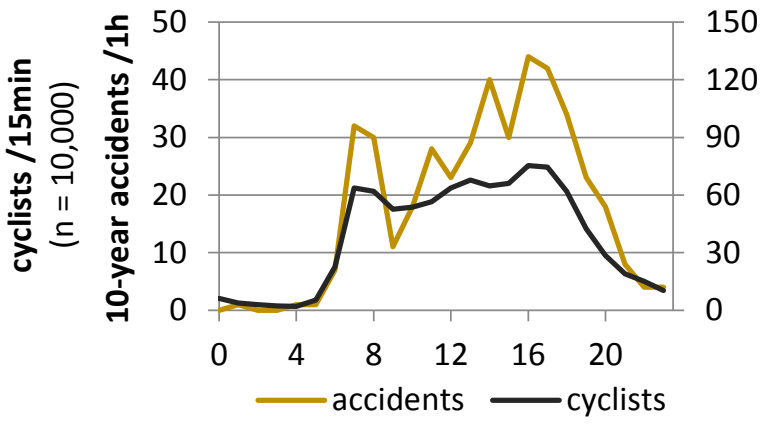

Figure 4. The simulated number of encounters per cyclist (left) compares well with the police-reported number of accidents related to cyclist count numbers (right): cyclist rush hours triggered high numbers of encounters (accidents), whereas in times of low traffic volumes, the number of encounters dropped disproportionally.

The maps in Figure 5 visualise the spatial distribution of simulated flows (left) and encounter densities (centre). The third map on the right shows the actual location of reported accidents.

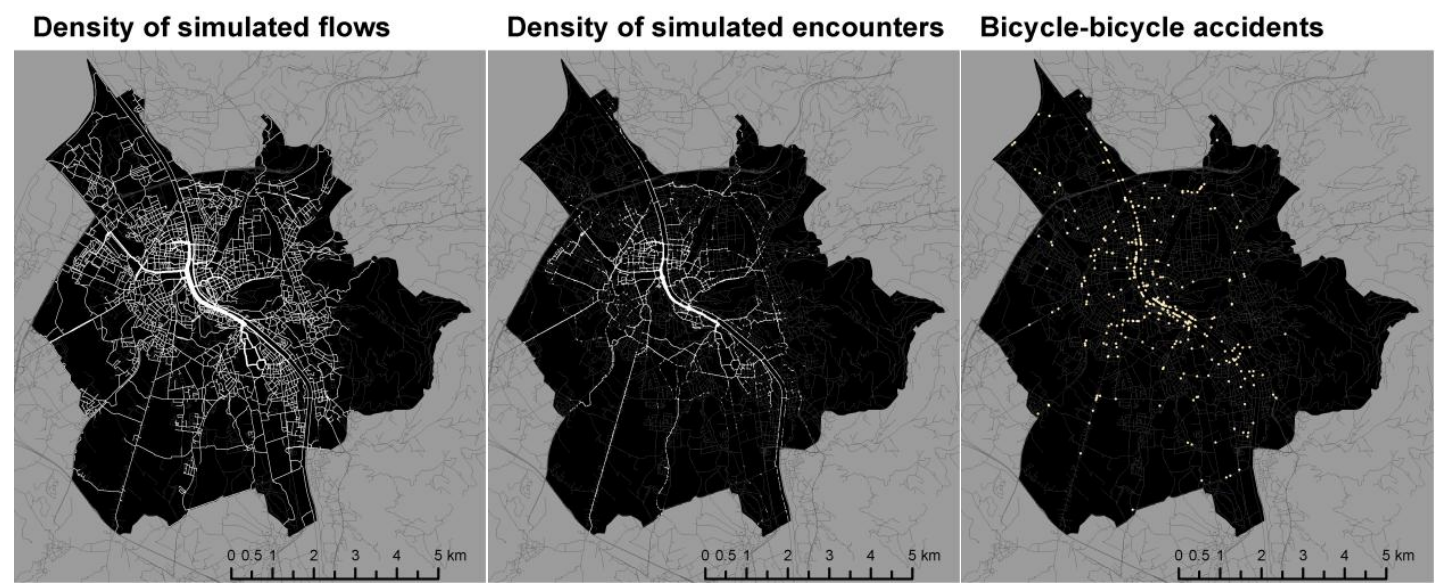

Figure 5. The maps visualise the bicycle commuting region of Salzburg, clipped to the city boundaries. Simulated bicycle flows for (left) and cyclist encounter densities (centre) are juxtaposed to the police records on locations of police reported bicycle-bicycle accidents (right).

Figure 6 shows the goodness of fit for simulated flows and encounter densities against accident events. In order to provide simulation data for the same 10-year duration as the observed accidents, the one-day simulation results were upscaled to 10 years. The reference for upscaling was the mean number of cyclists of two long-term counting stations at the day for which the simulation was calibrated (6 June 2013) in relation to the total bicycle count at these stations over one year. The conversion factor calculated this way amounted to a value of 185 for one year and 1850 for 10 years, respectively. Both datasets, the simulated flows and the simulated encounters, were therefore multiplied by a factor of 1850. A second-order polynomial function fitted the flows to the observed accident data with a high goodness of fit (adjusted $R^{2}=0.91$ ). All values were in the limits of the $68 \%$ confidence interval. Simulated encounters exhibited a linear relationship with the reported accidents, also with a high 
goodness of fit (adjusted $R^{2}=0.87$ ). Only half of the data points (12 of 24 ) fell into the $68 \%$ confidence interval of the regression line and only $80 \%$ of the data was within the $95 \%$ confidence interval, which suggested that the regression model may not be correct and additional factors should be considered to predict accidents. However, the residuals were dispersed randomly, which supported the linear relationship between encounters and accidents.
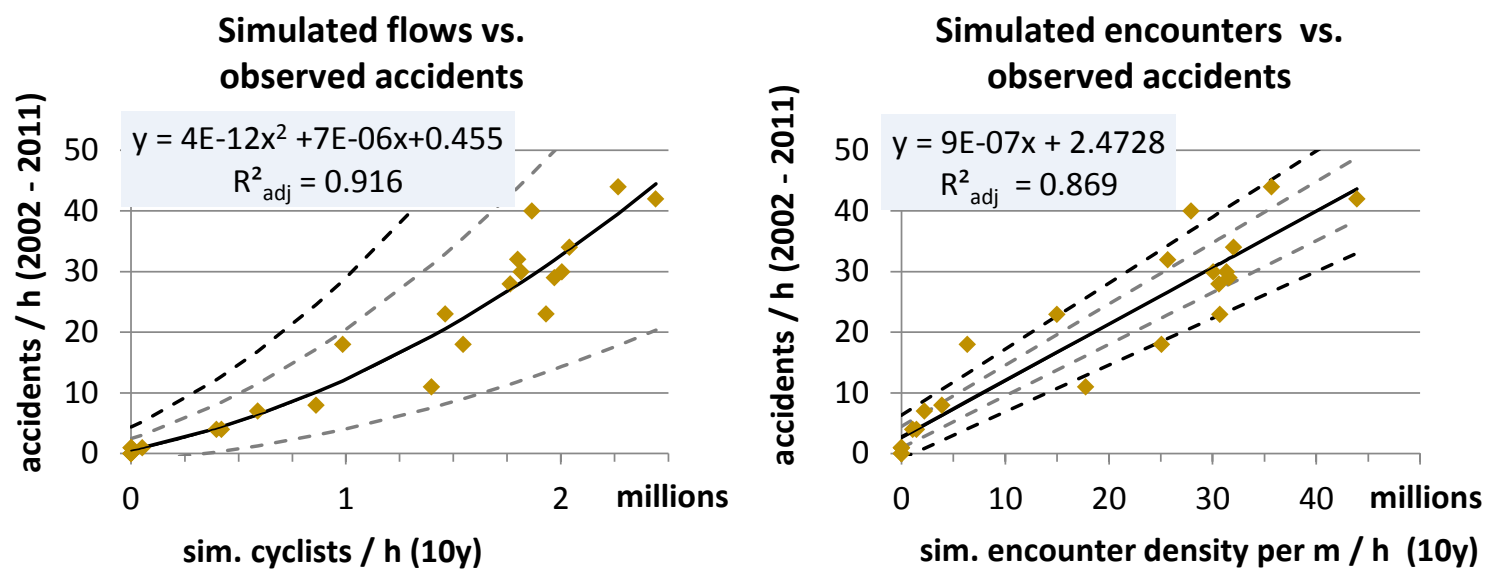

Figure 6. Simulated flows and simulated encounters are plotted against accident records: The hourly flows show a quadratic relation to the accidents (left); whereas the hourly encounter densities exhibit a linear relation (right). The dashed lines indicate the 68\% confidence interval (grey) and the $95 \%$ confidence interval (black).

\section{Discussion and Conclusions}

Validation of flows and encounters that were simulated with the Salzburg bicycle model showed a reasonably good fit with the observed accident data. The main implications of this good fit are threefold:

Firstly, the results affirm the quality of the simulation data and thus the validity of the Salzburg bicycle model for the purpose of simulating bicycle traffic flows of a city. Validity thereby has to be stated in reference to its specific purpose for which it was designed [33]. Unlike fine-scaled ABMs that are designed to study the interaction of traffic participants at intersections or other specific spatial contexts, the purpose of the Salzburg bicycle model is to simulate traffic flow patterns of the road network of an entire city. It therefore trades off behavioural realism at the local scale, e.g., giving way or adapting speed, with behaviour on the regional scale, e.g., finding a safe route. In the absence of observed city-wide bicycle traffic data, ABM has proven to be an approach that is well suited to estimating traffic patterns. Agent-based simulation modelling thus can be used as a means to overcome a lack of adequate bicycle traffic data, which is one of the main challenges in estimating bicycle accident risks [34].

Secondly, the results show a linear relation between simulated encounters and observed accidents, but a quadratic relation between simulated flows and accidents. This backs the first hypothesis of this paper that bicycle-bicycle accidents emerge from the population that is defined by encounters rather than by traffic flow. Exposure data usually refer to distance travelled, cycling travel time, number of bicycles at a certain location or the number of trips made [29,34]. All these data relate to traffic flows rather than encounters. However, our results suggest that the use of traffic flow as an exposure variable is actually a surrogate for encounters. A good reason for using traffic flow data in equation-based accident prediction models is that it can be acquired more easily than encounter data. This is especially true for the scale of a region or an entire city. Whereas traffic flow data are usually collected by means of a set of spatially distributed in-situ count stations [35], encounter data need a more elaborate collection technique, such as video analysis of a specific location [27]. Our results show 
that disaggregate agent-based models are of particular importance in this context, as they can simulate not only realistic city-wide flows but also city-wide encounters from traffic count data.

Thirdly, the excellent fit of simulated flows with accidents by a second-order polynomial function backs the theoretical considerations that led to the second hypothesis, i.e., that flows and encounters exhibit a non-linear relationship. The results of this research imply that increasing bicycle volumes leads to a disproportional increase in encounters and hence potential accidents. This finding at the first sight is not backed by the literature, as increasing traffic volume is usually accompanied with decreasing accident rates. Elvik et al. [36] explain this relation with better road standards and increased attention from drivers. Also the 'safety in numbers' phenomenon describes decreasing bicycle accident rates with increasing traffic volumes. Possible explanations relate to safer infrastructure for highly frequented bicycle routes [8,37] and increased attention of car drivers in response to high numbers of cyclists [7,30]. However, Bhatia and Wier [38] argue that any causal interpretation of aggregate statistics on the macroscale may be incorrect and needs to be closely examined at the local scale. Agent-based modelling has contributed to illuminate how the safety in numbers phenomenon can emerge from the behaviour of car drivers at the local scale [30]. A distinct feature of the agent-based model presented here is the focus on bicycle-bicycle encounters only, which is fundamentally different from the interaction between non-motorised and motorised vehicles [39]. In this respect our research compares well with Martin's [6] study on car-car accidents in relation to car traffic volumes. In line with the presented results, Martin found increasing accident rates for increased traffic volumes on a highway. The question thus remains how encounters are related to accidents between bicycles and whether bicycle-bicycle accidents differ from single bicycle or bicycle-car accidents. Schepers et al. [40] suggest a linear relation of single-bicycle accidents with bicycle flows, which further supports the use of encounters as a base for bicycle-bicycle accidents. Accidents between non-motorised and motorised vehicles also develop from encounters and thus also draw from the statistical population of encounters. Reasons for the contrary trend in accident numbers with respect to traffic flows may lie in the different mechanisms that turn an encounter into an accident.

Regardless of the question of whether flows or encounters are more adequate as exposure variables, the results are encouraging in terms of applying ABMs to estimating traffic patterns for an entire city. However, data scarcity limits rigorous model validation, especially in the city periphery, where only a few bicycle count stations are located. Whilst acknowledging this limitation, ABMs have the major benefit of capturing the spatial distribution of accident risks, where encounter densities are even more spatially accurate than flows. The simulation of data can be specifically valuable in the case of scarcity of adequate empirical data. In addition to that, ABMs are particularly well suited to integrating local context and behavioural information of individual road users [41]. The next step ahead in predicting accidents with ABM is thus to systematically analyse context-specific risk factors that are associated with an encounter, such as encounter angle, road type, traffic mode, weather, time of the day, or certain road user characteristics [2], and integrate these into ABM models.

Author Contributions: Gudrun Wallentin designed the study, conducted the analyses and wrote the manuscript. Martin Loidl contributed to the study design and processed the model input and validation data.

Conflicts of Interest: The authors declare no conflicts of interest.

\section{References}

1. Juhra, C.; Wieskötter, B.; Chu, K.; Trost, L.; Weiss, U.; Messerschmidt, M.; Malczyk, A.; Heckwolf, M.; Raschke, M. Bicycle accidents-Do we only see the tip of the iceberg? A prospective multi-centre study in a large german city combining medical and police data. Injury 2012, 43, 2026-2034. [CrossRef] [PubMed]

2. Van der Horst, A.R.A.; de Goede, M.; de Hair-Buijssen, S.; Methorst, R. Traffic conflicts on bicycle paths: A systematic observation of behaviour from video. Accid. Anal. Prev. 2014, 62, 358-368. [CrossRef] [PubMed]

3. Greibe, P. Accident prediction models for urban roads. Accid. Anal. Prev. 2003, 35, 273-285. [CrossRef] 
4. $\quad$ Eenink, R.; Reurings, M.; Elvik, R.; Cardoso, J.; Wichert, S.; Stefan, C. Accident Prediction Models and Road Safety Impact Assessment: Recommendations for Using These Tools; Institute for Road Safety Research: Leidschendam, The Netherlands, 2008.

5. Duivenvoorden, K. The Relationship between Traffic Volume and Road Safety on the Secondary Road Network: A Literature Review; Institute for road safety research: Leidschendam, Netherlands, 2010.

6. Martin, J.-L. Relationship between crash rate and hourly traffic flow on interurban motorways. Accid. Anal. Prev. 2002, 34, 619-629. [CrossRef]

7. Jacobsen, P.L. Safety in numbers: More walkers and bicyclists, safer walking and bicycling. Inj. Prev. 2003, 9, 205-209. [CrossRef] [PubMed]

8. Reynolds, C.; Harris, M.A.; Teschke, K.; Cripton, P.A.; Winters, M. The impact of transportation infrastructure on bicycling injuries and crashes: A review of the literature. Environ. Heal. 2009, 8, 47. [CrossRef] [PubMed]

9. Gregoriades, A.; Mouskos, K.C. Black spots identification through a bayesian networks quantification of accident risk index. Transp. Res. Part C Emerg. Technol. 2013, 28, 28-43. [CrossRef]

10. Vandenbulcke, G.; Dujardin, C.; Thomas, I.; Geus, B.D.; Degraeuwe, B.; Meeusen, R.; Panis, L.I. Cycle commuting in belgium: Spatial determinants and 're-cycling' strategies. Transp. Res. Part A Policy Pract. 2011, 45, 118-137. [CrossRef]

11. Vandenbulcke, G.; Thomas, I.; Int Panis, L. Predicting cycling accident risk in brussels: A spatial case-Control approach. Accid. Anal. Prev. 2014, 62, 341-357. [CrossRef] [PubMed]

12. Hankey, S.; Lindsey, G.; Wang, X.; Borah, J.; Hoff, K.; Utecht, B.; Xu, Z. Estimating use of non-motorized infrastructure: Models of bicycle and pedestrian traffic in minneapolis, mn. Landsc. Urban Plan. 2012, 107, 307-316. [CrossRef]

13. Oksanen, J.; Bergman, C.; Sainio, J.; Westerholm, J. Methods for deriving and calibrating privacy-preserving heat maps from mobile sports tracking application data. J. Transp. Geogr. 2015, 48, 135-144. [CrossRef]

14. Palmer, A.J.; Si, L.; Gordon, J.M.; Saul, T.; Curry, B.A.; Otahal, P.; Hitchens, P.L. Accident rates amongst regular bicycle riders in tasmania, australia. Accid. Anal. Prev. 2014, 72, 376-381. [CrossRef] [PubMed]

15. Aertsens, J.; de Geus, B.; Vandenbulcke, G.; Degraeuwe, B.; Broekx, S.; De Nocker, L.; Liekens, I.; Mayeres, I.; Meeusen, R.; Thomas, I.; et al. Commuting by bike in belgium, the costs of minor accidents. Accid. Anal. Prev. 2010, 42, 2149-2157. [CrossRef] [PubMed]

16. De Geus, B.; Vandenbulcke, G.; Int Panis, L.; Thomas, I.; Degraeuwe, B.; Cumps, E.; Aertsens, J.; Torfs, R.; Meeusen, R. A prospective cohort study on minor accidents involving commuter cyclists in belgium. Accid. Anal. Prev. 2012, 45, 683-693. [CrossRef] [PubMed]

17. Nelson, T.A.; Denouden, T.; Jestico, B.; Laberee, K.; Winters, M. Bikemaps.Org: A global tool for collision and near miss mapping. Front. Public Heal. 2015, 3. [CrossRef] [PubMed]

18. Wallentin, G.; Loidl, M. Agent-based bicycle traffic model for salzburg city. GI_Forum J. Geogr. Inf. Sci. 2015, 2015, 558-566. [CrossRef]

19. Wallentin, G.; Car, A. A framework for uncertainty assessment in simulation models. Int. J. Geogr. Inf. Sci. 2012, 27, 408-422. [CrossRef]

20. Behrisch, M.; Bieker, L.; Erdmann, J.; Krajzewicz, D. Sumo-simulation of urban mobility. In Proceedings of the Third International Conference on Advances in System Simulation (SIMUL 2011), Barcelona, Spain, 23-28 October 2011.

21. Wahle, J.; Bazzan, A.L.C.; Klügl, F.; Schreckenberg, M. The impact of real-time information in a two-route scenario using agent-based simulation. Transp. Res. Part C Emerg. Technol. 2002, 10, 399-417. [CrossRef]

22. Dallmeyer, J.; Schumann, R.; Lattner, A.D.; Timm, I.J. Don't go with the ant flow: Ant-inspired traffic routing in urban environments. J. Intell. Transp. Syst. Technol. Plan. Oper. 2015, 19. [CrossRef]

23. Balmer, M.; Cetin, N.; Nagel, K.; Raney, B. Towards truly agent-based traffic and mobility simulations. In Proceedings of the Third International Joint Conference on Autonomous Agents and Multiagent Systems, New York, NY, USA, 23 July 2004; IEEE Computer Society: New York, NY, USA, 2004; Volume 1, pp. 60-67.

24. Waraich, R.; Charypar, D.; Balmer, M.; Axhausen, K. Performance improvements for large-scale traffic simulation in MATSim. In Computational Approaches for Urban Environments; Helbich, M., Jokar Arsanjani, J., Leitner, M., Eds.; Springer International Publishing: Cham, Switzerland, 2015; Volume 13, pp. 211-233.

25. Batty, M.; Torrens, P.M. Modelling and prediction in a complex world. Futures 2005, 37, 745-766. [CrossRef]

26. Chen, B.; Cheng, H.H. A review of the applications of agent technology in traffic and transportation systems. IEEE Trans. Intell. Transp. Syst. 2010, 11, 485-497. [CrossRef] 
27. Laureshyn, A.; Svensson, Å.; Hydén, C. Evaluation of traffic safety, based on micro-level behavioural data: Theoretical framework and first implementation. Accid. Anal. Prev. 2010, 42, 1637-1646. [CrossRef] [PubMed]

28. Archer, J.; Kosonen, I. The potential of micro-simulation modelling in relation to traffic safety assessment. In Proceedings of the ESS Conference Proceedings, Hamburg, Germany, 2000; Citeseer: Hamburg, Germany, 2000.

29. Daniels, S.; Brijs, T.; Nuyts, E.; Wets, G. Extended prediction models for crashes at roundabouts. Saf. Sci. 2011, 49, 198-207. [CrossRef]

30. Thompson, J.; Savino, G.; Stevenson, M. Reconsidering the safety in numbers effect for vulnerable road users: An application of agent-based modeling. Traffic Inj. Prev. 2015, 16, 147-153. [CrossRef] [PubMed]

31. Wilensky, U. Netlogo; Center for Connected Learning and Computer-Based Modeling, Northwestern University: Evanston, IL, USA, 1999.

32. Okabe, A.; Satoh, T.; Sugihara, K. A kernel density estimation method for networks, its computational method and a gis-based tool. Int. J. Geogr. Inf. Sci. 2009, 23, 7-32. [CrossRef]

33. Barlas, Y. Formal aspects of model validity and validation in system dynamics. Syst. Dyn. Rev. 1996, 12, 183-210. [CrossRef]

34. Vanparijs, J.; Int Panis, L.; Meeusen, R.; de Geus, B. Exposure measurement in bicycle safety analysis: A review of the literature. Accid. Anal. Prev. 2015, 84, 9-19. [CrossRef] [PubMed]

35. Leduc, G. Road traffic data: Collection methods and applications. Work. Pap. Energy Transp. Clim. Chang. 2008, 1, 1-49.

36. Elvik, R.; Vaa, T.; Erke, A.; Sorensen, M. The Handbook of Road Safety Measures; Emerald Group Publishing: Oslo, Norway, 2009.

37. Harris, M.A.; Reynolds, C.C.; Winters, M.; Cripton, P.A.; Shen, H.; Chipman, M.L.; Cusimano, M.D.; Babul, S.; Brubacher, J.R.; Friedman, S.M. Comparing the effects of infrastructure on bicycling injury at intersections and non-intersections using a case-Crossover design. Inj. Prev. 2013, 19, 303-310. [CrossRef] [PubMed]

38. Bhatia, R.; Wier, M. "Safety in numbers" re-examined: Can we make valid or practical inferences from available evidence? Accid. Anal. Prev. 2011, 43, 235-240. [CrossRef] [PubMed]

39. Thomas, B.; DeRobertis, M. The safety of urban cycle tracks: A review of the literature. Accid. Anal. Prev. 2013, 52, 219-227. [CrossRef] [PubMed]

40. Schepers, P.; Agerholm, N.; Amoros, E.; Benington, R.; Bjørnskau, T.; Dhondt, S.; de Geus, B.; Hagemeister, C.; Loo, B.P.Y.; Niska, A. An international review of the frequency of single-bicycle crashes (sbcs) and their relation to bicycle modal share. Inj. Prev. 2015, 21, e138-e143. [CrossRef] [PubMed]

41. Bonabeau, E. Agent-based modeling: Methods and techniques for simulating human systems. Proc. Natl. Acad. Sci. USA 2002, 99, 7280-7287. [CrossRef] [PubMed]

(C) 2016 by the authors; licensee MDPI, Basel, Switzerland. This article is an open access article distributed under the terms and conditions of the Creative Commons Attribution (CC-BY) license (http://creativecommons.org/licenses/by/4.0/). 